\title{
Experimental study of atmosphere temperature and humidity under controlled conditions at laboratory scale
}

\section{Estudio experimental de la atmósfera a escala de laboratorio bajo condiciones controladas de temperatura y de humedad}

\author{
H.S. Buenahora 2 , O.J. Tíjaro ${ }^{1,2}$, A. Ballesteros², Y. Torres ${ }^{2 *}$ \\ 1. Escuela de Ingenierías Eléctrica, Electrónica y Telecomunicaciones, \\ 2. GOTS, Grupo de Óptica y Tratamiento de Señales, Escuela de Física, \\ Universidad Industrial de Santander, A.A. 678, 680002 Bucaramanga, Colombia. \\ (*) E-mail: otijaro@gmail.com \\ Received: 01/12/2017 Accepted: 02/03/2018 \\ DOI: 10.7149/OPA.51.1.49049
}

\begin{abstract}
:
This paper presents analysis of spatial and temporal changes in the wavefront of a laser beam to short horizontal distances at low altitude and laboratory scale. The atmosphere through optical propagation path is subjected to varying conditions of humidity and temperature independently controlled. Experimental results were conducted in GOTS-UIS-Colombia compared with those obtained by numerical simulations, developed in FAU-USA.
\end{abstract}

Key words: Correlation, Scintillation, Inner Scale, Atmospheric Turbulence, $C_{n}^{2}$

\section{RESUMEN:}

Este trabajo presenta los análisis de las variaciones espaciales y temporales en el frente de onda de un haz láser a cortas distancias horizontales, a baja altura y a escala de laboratorio. La atmósfera que atraviesa el camino óptico de propagación es sometida a condiciones variables de humedad y temperatura controladas independientemente. Los resultados experimentales fueron comparados con los obtenidos mediante simulación numérica en el GOTS-UIS-Colombia, a partir del desarrollo computacional realizado previamente en FAU-USA.

Palabras clave: Correlación, Centelleo, Escala interna, Turbulencia atmosférica, $C_{n}^{2}$

\section{REFERENCES AND LINKS / REFERENCIAS Y ENLACES}

[1] G. DiComo, M. Helle, J. Peñano, A. Ting, A. Schmitt-Sody, J. Elle, "Implementation of a long range, distributed-volume, continuously variable turbulence generator," Applied Optics 55, 5192-7 (2016).

[2] J. C. Contreras Lopez, A. Ballesteros Diaz, O. J. Tíjaro Rojas y Y. Torres Moreno, “Atmospheric turbulence temperature on the laser wavefront properties," IOP Conf. Series: Journal of Physics: Conf. Series 850, (2017).

[3] J. Villamizar Conde, M. F. Herreño, A. Ballesteros Díaz, O. J. Tíjaro Rojas, Y. Torres Moreno, "Efectos de la humedad relativa en la propagación de un haz láser a escala de laboratorio," Graduate work in Electronic engineering, UIS, Colombia, (2016).

[4] W.T. Rhodes, "Time-average Fourier telescopy: a scheme for high-resolution imaging through horizontal-path turbulence," Applied Optics 51, A11-A16, (2012).

[5] N. Randunu Pathirannehelage, "Imaging through ground-level Turbulence by Fourier Telescopy: Simulations and preliminary experiments," PhD. Dissertation, FAU, USA, 89, (2015).

[6] A. Consortini, Y.Y. Sun, C. Innocenti, Z.P. Li, "Measuring inner scale of atmospheric turbulence by angle of arrival and scintillation," Optics Communications 216, 19-23 (2003). 


\section{Introduction}

Turbulence in lower atmosphere is a phenomenon of great importance in scientific community because its implications on different areas of study such as optical communications, mapping, pollutants dispersion, among other [1]. Experimental works have shown that physical variables like temperature [2] and humidity [3] can be characterized. These studies suggest an empirical approach, i.e., laser beam behavior is observed on its propagation, when subjected to varying environmental conditions at laboratory scale.

A theoretical model, developed by Rhodes [4] and implemented numerically by N. Randunu P. [5] at Florida Atlantic University (FAU), was used to simulate atmospheric turbulence effects. To check theoretical studies discussed above, experiments that establish a relationship between these results and theoretical simulation with temperature and humidity conditions were performed in optical path and generated turbulence in atmosphere arise.

Therefore, implemented software worked with different values for constant structure refractive index $C_{n}^{2}$ to obtain wavefront patterns at a defined distance from the source [5]. We used controlled temperature and humidity variables per conducted experimental tests. In turn, cross-correlation is evaluated between simulated 2D patterns and images captured by experimental methods to verify their correspondence.

\section{Methodology}

The physical quantities, temperature and humidity, were controlled independently by electronic designed boards. Because of atmosphere nature, control means are not efficient to isolate same generated turbulent medium, consequently, we made use of a metal tube (to try of isolating some variables) with dimensions: 1 $\mathrm{m}$ long, $7 \mathrm{~cm}$ inner diameter and $7.5 \mathrm{~cm}$ external diameter (see Figure 1), owned by the laboratory of Optics and Signal Processing Group of University Industrial of Santander (GOTS-UIS) which was named Turbulator.

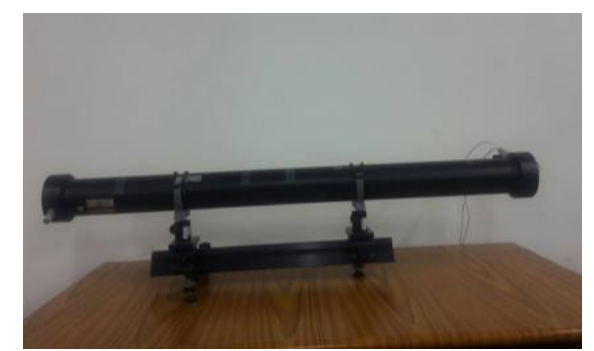

Fig 1. Turbulator photography, from reference [2]

Before starting tests of wavefront measurements, a characterization of variable conditions in environment were conducted, in order to observe Turbulator response to the turbulence generator system.

Relative humidity was the first variable where we made measurements along the axis of laser beam propagation and with different relative humidity values that were generate from input steam at one end of turbulator. The results describe a curve shown in Figure 2. Different distances presented here indicate proximity of sensor to emission source, where if closer to the source, more moisture is registered.

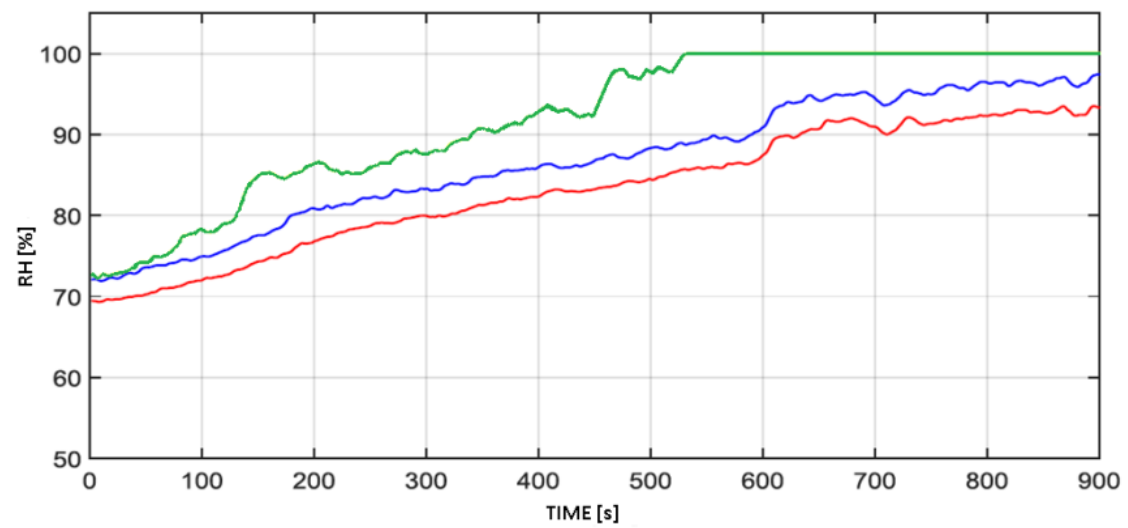

Fig 2. Relative humidity variation along turbulator (Green: $10 \mathrm{~cm}$, Blue: $60 \mathrm{~cm}$, Red: $95 \mathrm{~cm}$ ) [2]. 
To these tests, another glass structure was also proposed (called Glass Container Parallelepiped, GCP [2]), which made use of bulbs located as indicated in Figure 3 for increasing temperature in the middle of GCP. In this structure, is sought from higher volume a further convection temperature and greater gradient in its walls. Temperature characterization inside GCP is shown in Figure 3.

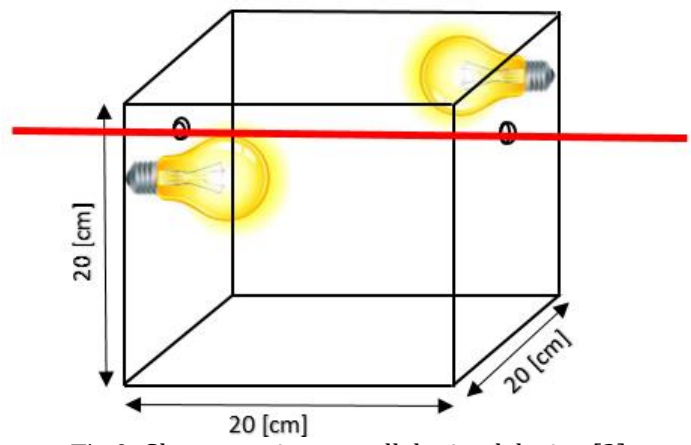

Fig 3. Glass container parallelepiped design [2].

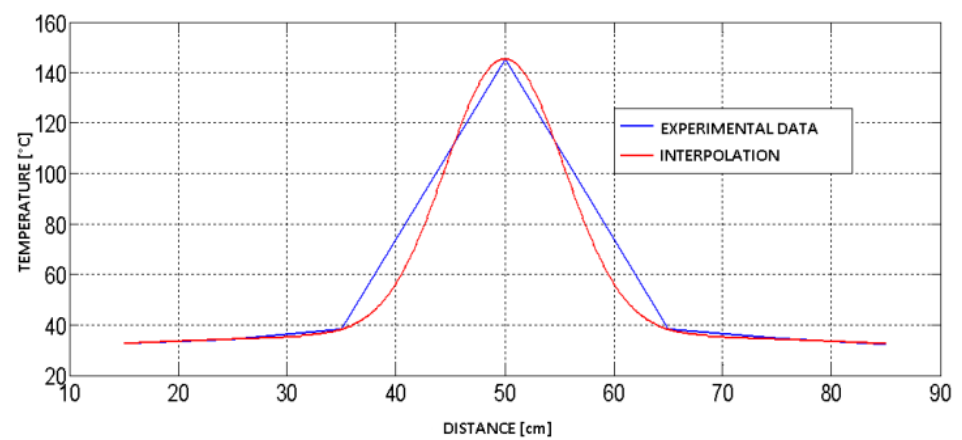

Fig 4. Sensors spatial position vs Temperature characteristic curve inside GCP. Position is indicated for sensors close to laser beam optical path [2].

With the experimental results documented in references [2,3], we proceeded to determine the value of scintillation $\sigma_{I}^{2}$ (see Equation 1), inner scale $l_{0}$ (see Equation 2) and structure refractive index parameter $C_{n}^{2}$ (see Equation 3), for each realized experiment. Subsequently, values were entered as parameters of implemented model, by performing two tests: One, introducing only $C_{n}^{2}$ and, another entering values of internal scale and $C_{n}^{2}$, both to study in detail the relationships between experimental results and theoretical model by numerical simulation.

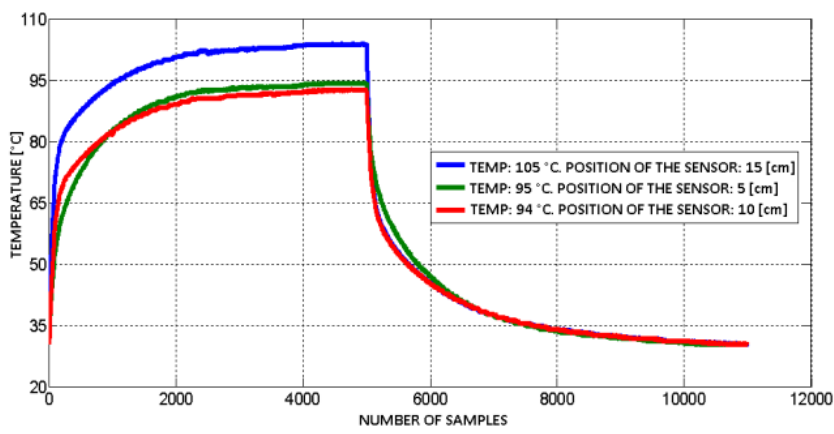

Fig 5. Time vs Temperature characteristic curve in the GCP for different sensors across the laser beam [2].

For scintillation index [6], we took average intensity $(I)$ fluctuations so.

$$
\sigma_{I}^{2}=\frac{\left.<I^{2}>-<I\right\rangle^{2}}{<I>^{2}}
$$

Where $<>$ means temporal average value. Then, the inner scale of turbulence, defined in Equation 2, is a scale where energy of atmospheric turbulence is dissipated, internal scale is critical to determining heat fluxes on surfaces [6]. 


$$
l_{0}=1.08 L\left(\frac{<\alpha^{2}>}{\sigma_{I}{ }^{2}}\right)^{\frac{1}{2}}
$$

Where $\alpha$ is the beam arrival angle and, $\sigma_{I}^{2}$ is scintillation index calculated as in Equation 1 [6]. $L$ is the distance between output beam and wavefront sensor.

Supposing a plane wave that propagates through homogeneous and isotropic turbulence, the structure constant of refractive index (see, Equation 3 ) is defined, because all tests are within limits of geometrical optics approximation $\mathrm{L}<<l_{0} / \lambda$, being $\lambda$ the wavelength.

$$
<\alpha^{2}>=<\beta^{2}>=3.28 C_{n}{ }^{2} L l_{0}^{-1 / 3}
$$

Where $\mathrm{L}$ is propagation path length of laser beam and $\beta$ is beam arrival angle too [6].

\section{Results}

\section{3. a. Ratio of simulation to experimental results using GCP temperature controlled. Introducing $C_{n}^{2}$.}

Given temperature conditions in Table 1 and keeping constant this variable, 1800 samples of $1 \mathrm{~Hz}$ wavefront were acquired at a propagation distance of $3.97 \mathrm{~m}$. In Figure 6, local variations of $C_{n}^{2}$ at $45^{\circ} \mathrm{C}$ and $105^{\circ} \mathrm{C}$ are shown.
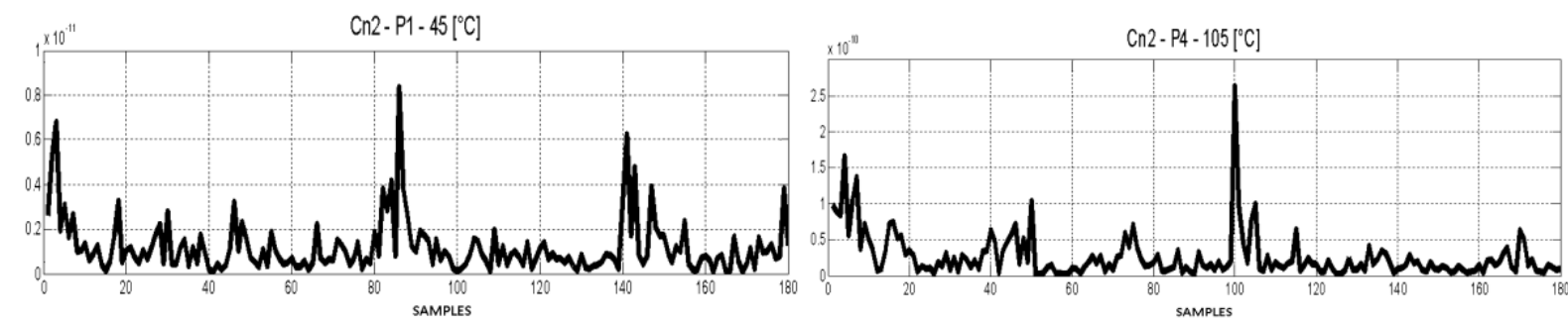

Fig 6. $\boldsymbol{C}_{n}^{2}$ obtained for two different tests on the GCP at constant temperatures. Left: $\mathrm{T}=45^{\circ} \mathrm{C}$. Right: $\mathrm{T}=105^{\circ} \mathrm{C}$.

In local variations calculus for $C_{n}^{2}$, we took groups of 10 samples, obtaining a total of 180 values that fluctuated on average, for all tests as detailed in Table 1.

TABLE $1 . \boldsymbol{C}_{n}^{2}$ average for constant temperatures of $45^{\circ} \mathrm{C}$ and $105^{\circ} \mathrm{C}$.

\begin{tabular}{|c|c|}
\hline Test & $\boldsymbol{C}_{\boldsymbol{n}}^{2}$ Average $\left[\boldsymbol{m}^{\frac{-2}{3}}\right]$ \\
\hline $\mathbf{P 1}-\mathbf{4 5}^{\circ} \mathbf{C}$ & $1.1982 \mathrm{e}-12$ \\
\hline $\mathbf{P 3}-\mathbf{1 0 5}^{\circ} \mathbf{C}$ & $2.0655 \mathrm{e}-11$ \\
\hline
\end{tabular}

A sample of experimental realization at constant temperature of $105^{\circ} \mathrm{C}$ in the GCP is shown in Figure 7A), where $C_{n}^{2}$ has an average value as previously calculated (see Table 1). It was also introduced the correspondent numerical simulation shown in Figure 7B).

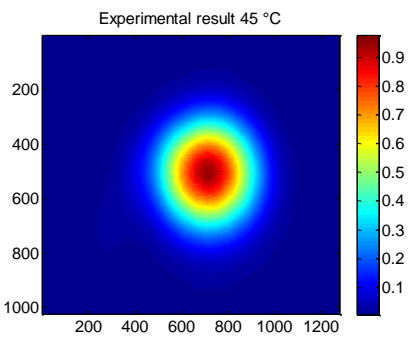

A)

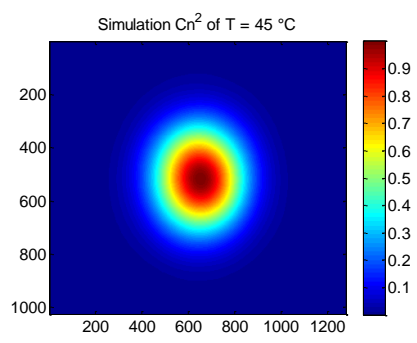

B)

Fig 7. A) Experimental realization at $105^{\circ} \mathrm{C}$ inside the GCP. B) Simulation results using $C_{n}^{2}$ averaged.

To compare numerical and experimental test, we acquired samples under previously described conditions. On the other hand, these estimated parameters were introduced in a numerical algorithm where a wavefront realization denotes a wavefront acquisition [5]. With both data (experimental obtained and 
numerical images), we used to analyze the behavior means cross correlation. In this case, cross-correlation peak obtained was $69.09 \%$ (see Figure 8), which show that more physical variables have to be included in the model to improve the precision.

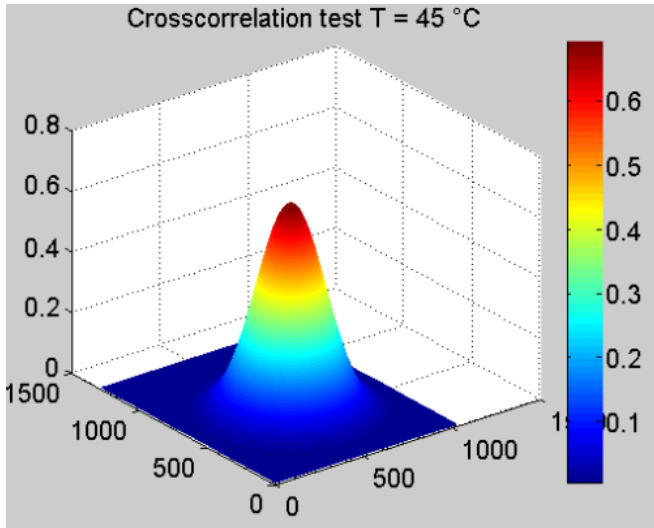

Fig 8. Cross-correlation between the experimental and simulation results for $C_{n}^{2}=1.1982 \mathrm{e}-12\left[\mathrm{~m}^{\frac{-2}{3}}\right]$.

Similarly, a realization of experiment implemented at constant temperature of $105^{\circ} \mathrm{C}$ in the GCP (see Figure 9A), where $C_{n}^{2}$ value was an average value previously found in Table 1 . It was also introduced in numerical simulation obtaining following result (see Figure 9B).

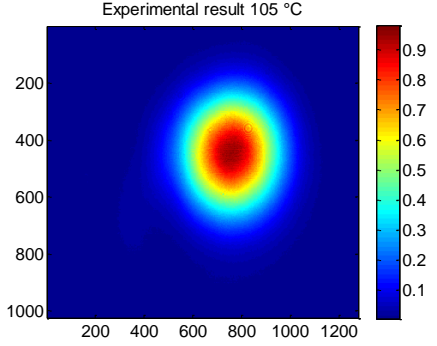

A)

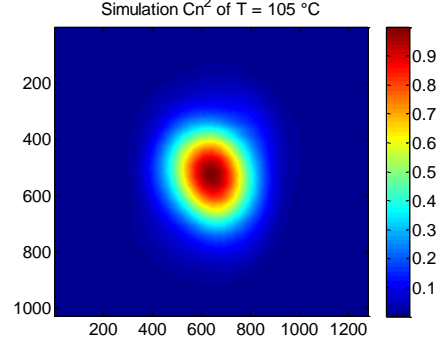

B)

Fig 9. A) Experimental realization at $105^{\circ} \mathrm{C}$ inside the GCP. B) Simulation results using $C_{n}^{2}$ averaged.

In addition, we performed the respective cross-correlation between the experimental results and their respective results obtained by numerical simulation, finding a peak correlation of $71.84 \%$ (see Figure 10 ).

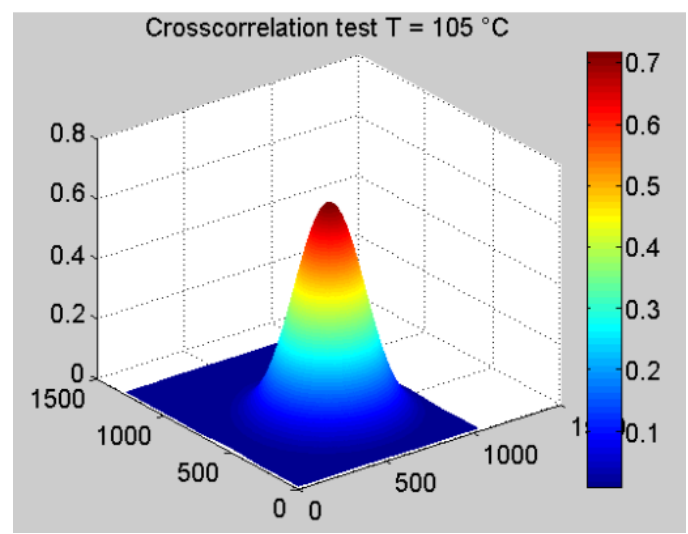

Fig 10. Cross-correlation between the experimental and simulation results for $C_{n}^{2}=2.0655 \mathrm{e}-11\left[\mathrm{~m}^{\frac{-2}{3}}\right]$.

With these two main results is expected to further analyze the numerical model, and achieve introduce more physical variables as i.e. the temperature structure parameter, $C_{T}^{2}$ since the obtained results have relatively low correlation. 


\section{3. b. Relationship between simulation and experimental results for relative humidity controlled} inside the Turbulator. Introducing $C_{n}^{2}$.

In tests of relative humidity, we also selected two tests (with the same sampling characteristics contained in section 3.a.) and with previous environmental conditions. The naming convention for different test in Figure 11 are: standard for the first one and P6 for the last.

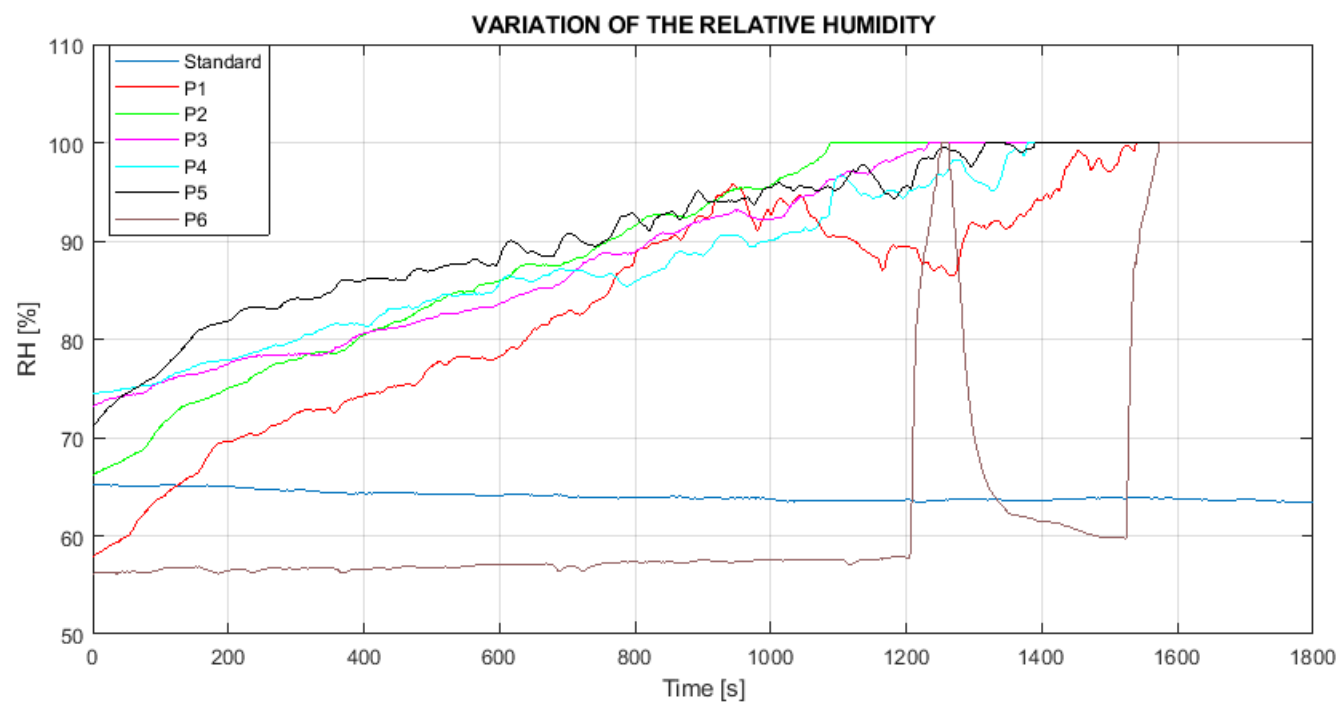

Fig 11. Relative humidity recorded for each Turbulator test.

Notably, to find $C_{n}^{2}$ values in P6 test (see black plot into Figure 11), data were taken during 1200 seconds, and up to that time the relative humidity was maintained constant.
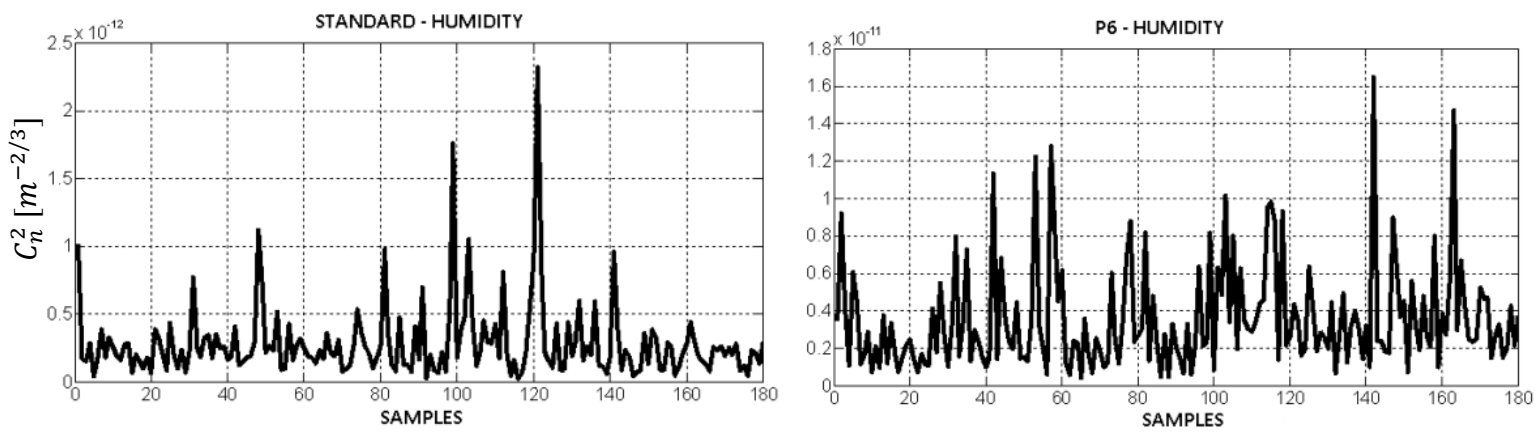

Fig 12. $\boldsymbol{C}_{\boldsymbol{n}}^{2}$ obtained for two different tests on the turbulator at constant temperatures. Left: Standard test $=65 \%$. Right: P6 test $=$ $58 \%$.

$C_{n}^{2}$ average values of fluctuations in each test are listed in Table 2:

TABLE 2. $\boldsymbol{C}_{n}^{2}$ average for constant relative humidities of $65 \%$ and $58 \%$.

\begin{tabular}{|c|c|}
\hline Test & $\boldsymbol{C}_{\boldsymbol{n}}^{2}$ Average $\left[\boldsymbol{m}^{\frac{-2}{3}}\right]$ \\
\hline Standard 65\% & $2.8269 \mathrm{e}-13$ \\
\hline $\mathbf{P 6 - 5 8 \%}$ & $3.4695 \mathrm{e}-12$ \\
\hline
\end{tabular}

With table 2 values, we selected atmospheric experimental realizations, which had a $C_{n}^{2}$ averaged (like results in Figure 13A). Use of numerical model was made with the respective $C_{n}^{2}$ and simulated image is shown in Figure 13B). 


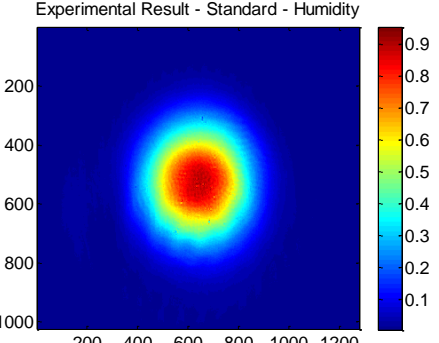

A)

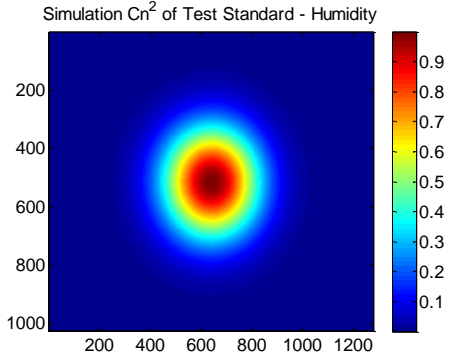

B)

Fig 13. A) Turbulator experimental result. B) Numerical simulation using $C_{n}^{2}$ averaged.

For standard test, the cross-correlation, between these two images became 68.96\% (see Figure 14).

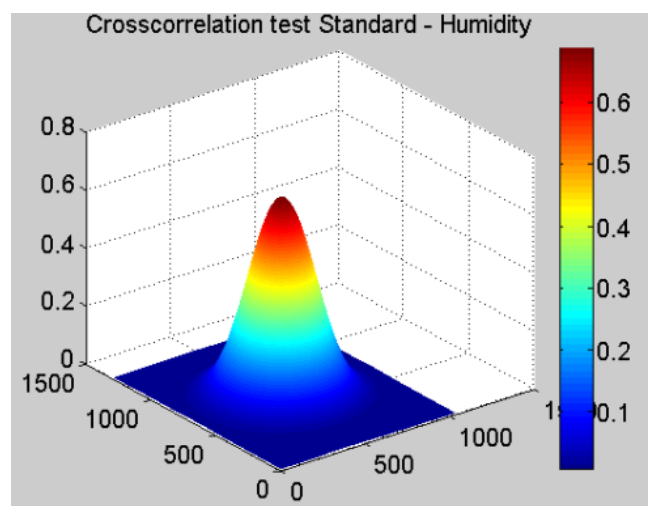

Fig 14. Cross-correlation between the experimental and simulation results for $C_{n}^{2}=2.8269 \mathrm{e}-13\left[\mathrm{~m}^{\frac{-2}{3}}\right]$.

As discussed above, for P6 test 1200 samples were taken, since, at that time a constant relative humidity getting $C_{n}^{2}$ averaged as shown in Table 2. Just as an image where was guaranteed a $C_{n}^{2}$ averaged and their numerical simulation with available simulation model (see figure 15).

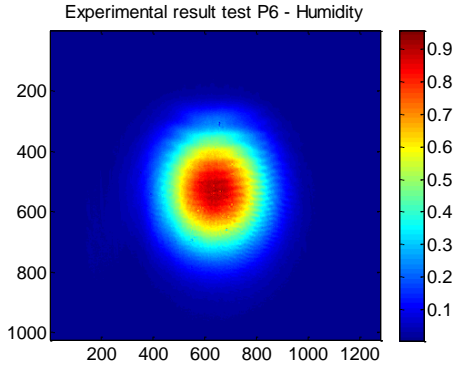

A)

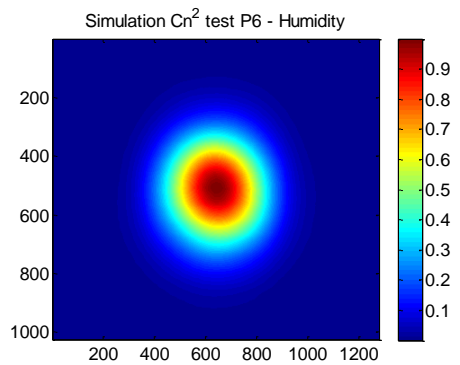

B)

Fig 15. A) Turbulator experimental result. B) Numerical simulation using $C_{n}^{2}$ averaged.

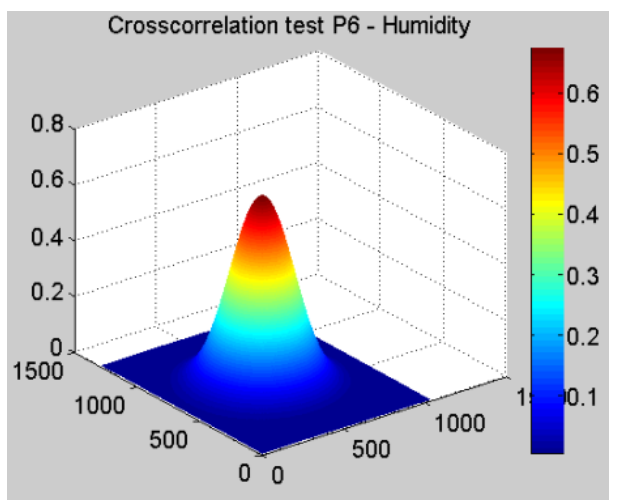

Fig 16. Cross-correlation between the experimental and simulation results for $C_{n}^{2}=3.4695 \mathrm{e}-12\left[\mathrm{~m}^{\frac{-2}{3}}\right]$. 
The cross-correlation for this case is $67.62 \%$ (see Figure 16). These results allowed us to approach to hypothesis that only $C_{n}^{2}$ no proper operation into numerical model, so it is necessary to provide to FAU model another parameter (see 3.c. and 3.d. section), the inner scale $l_{0}$ of the atmospheric turbulence.

3. c. Relationship between simulation and experimental results for temperature controlled inside GCP. Introducing $C_{n}^{2}$ and $\boldsymbol{l}_{\mathbf{0}}$.

After analyzing above results, we proceeded to find inner scale values of tests at constant temperature of $45^{\circ} \mathrm{C}$ and $105^{\circ} \mathrm{C}$. We were taken 180 inner scale values for each experiment to evaluate average fluctuation in the numerical simulation model (same as in A and B sections). The results are shown in Figure 17.
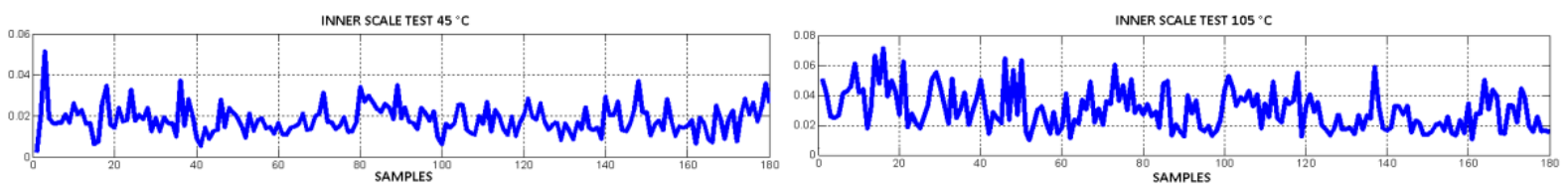

Fig 17. Inner scale obtained on GCP at constant temperatures. Left: $\mathrm{T}=45^{\circ} \mathrm{C}$. Right: $\mathrm{T}=105^{\circ} \mathrm{C}$.

We take 180 inner scale values for each experimental test to evaluate average fluctuation in numerical simulation model (with the same procedure implemented in 3.a. and 3.b. sections). The results are shown in Table 3.

TABLE 3. Inner scale average for constant temperatures of $45^{\circ} \mathrm{C}$ and $105^{\circ} \mathrm{C}$.

\begin{tabular}{|c|c|}
\hline Test & $\boldsymbol{l}_{\mathbf{0}}$ Average $[\mathrm{mm}]$ \\
\hline $\mathbf{P} 1-\mathbf{4 5}^{\circ} \mathbf{C}$ & 0.0183 \\
\hline $\mathbf{P 3}-\mathbf{1 0 5}^{\circ} \mathbf{C}$ & 0.0392 \\
\hline
\end{tabular}

With inner scale averaged for each of two tests at constant temperature, numerical simulation executed and, obtained image is shown in Figure 18A).

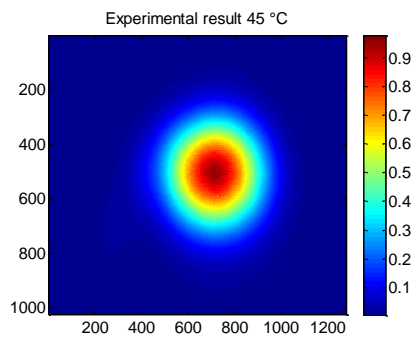

A)

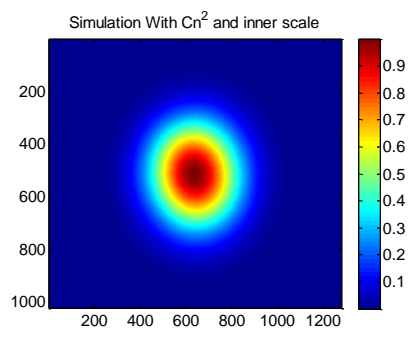

B)

Fig 18. A) Experimental results at $45^{\circ} \mathrm{C}$ in GCP. B) Simulation using $C_{n}^{2}$ and $l_{0}$ averaged.

Getting a cross-correlation peak of $68.44 \%$ (see Figure 19), which does not vary much with respect to results in section 3.a. where it only was introduced $C_{n}^{2}$.

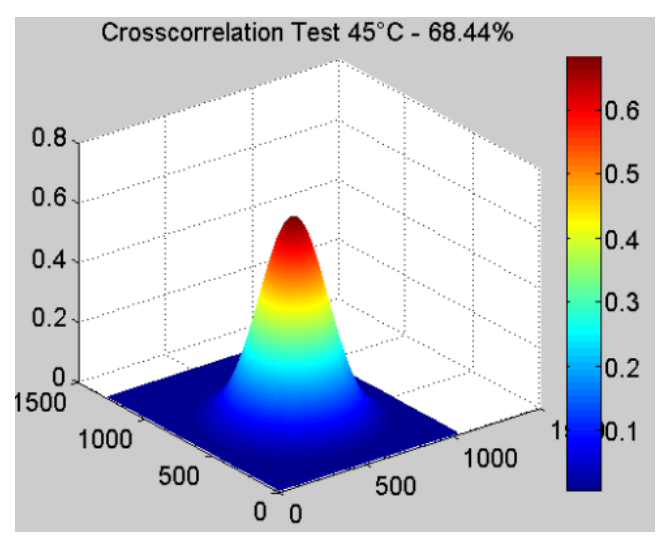

Fig 19. Cross-correlation between experimental and simulation results with $C_{n}^{2}=1.1982 \mathrm{e}-12\left[\mathrm{~m}^{\frac{-2}{3}}\right]$ and $l_{0}=0.0183[\mathrm{~mm}]$. 
Variable most altered was temperature, which incremented until $105^{\circ} \mathrm{C}$, it had a very strong $C_{n}^{2}$ and larger inner scale compared to $45^{\circ} \mathrm{C}$ test, therefore in the numerical simulation, occurs greater alteration as shown in figure 20.

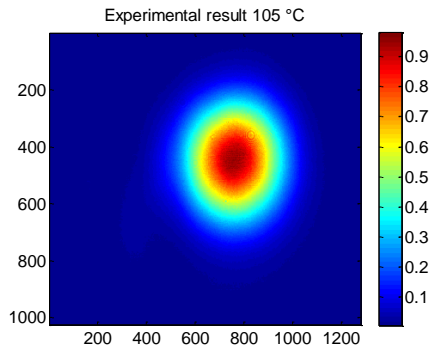

A)

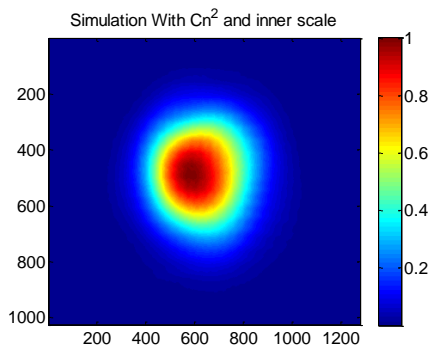

B)

Fig 20. A) Experimental $105^{\circ} \mathrm{C}$ test inside GCP. B) Simulation using $C_{n}^{2}$ and $l_{0}$ averaged.

In this case, cross-correlation peak had $57.21 \%$ (see Figure 21) lower result compared with section 3.a. where it was $71.84 \%$.

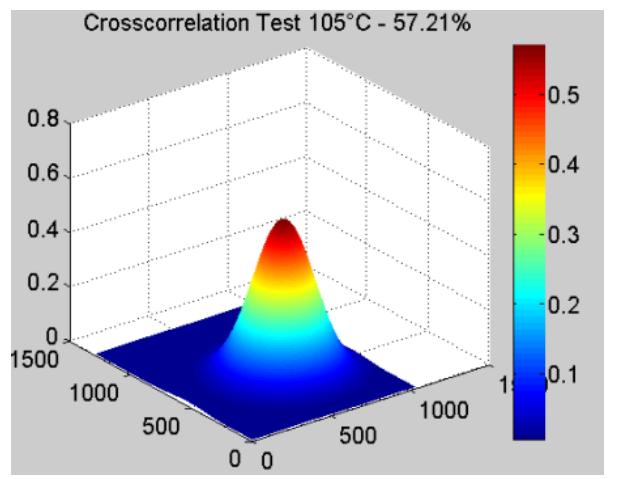

Fig 21. Cross-correlation between experimental and simulation results with $C_{n}^{2}=2.0655 \mathrm{e}-11\left[\mathrm{~m}^{\frac{-2}{3}}\right]$ and $l_{0}=0.0392[\mathrm{~mm}]$.

\section{3. d. Relationship between simulation and experimental results for relative humidity in turbulator.} Introducing $C_{n}{ }^{2}$ and $l_{0}$.

We also executed experiments with constant relative humidities for standard (58\%) and P6 (65\%) tests, finding inner scale for 1800 realizations at $1[\mathrm{~Hz}]$.
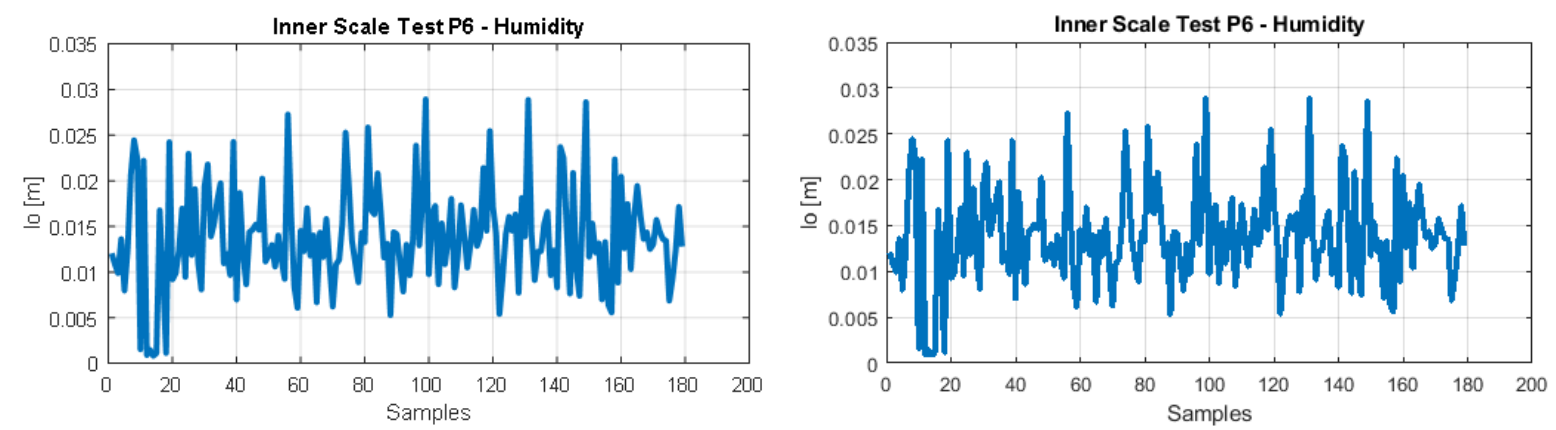

Fig 22. Inner scale obtained in two different tests inside turbulator under constant relative humidities. Left: Standard test $=65 \%$. Right: P6 test $=58 \%$.

The inner scale average fluctuation of each one was found, obtaining values shown in Table 4. 
TABLE 4. Inner scale average for constant relative humidities of $65 \%$ and $58 \%$.

\begin{tabular}{|c|c|}
\hline Test & $\boldsymbol{l}_{\mathbf{0}}$ Average [mm] \\
\hline Standard - 65\% & 0.0136 \\
\hline P6 - 58\% & 0.0090 \\
\hline
\end{tabular}

Initially we calculated inner scale of standard test and then inserted into numerical model. Consequences are shown in Figure 23B).

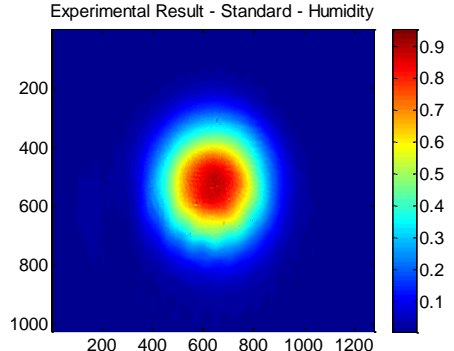

A)

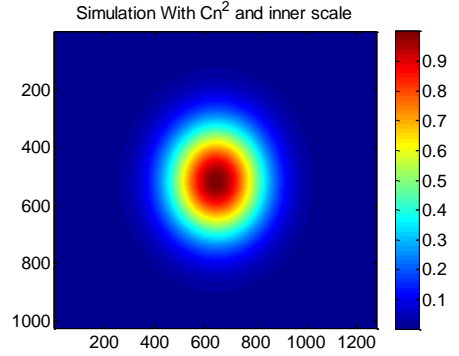

B)

Fig 23. A) Experimental results in turbulator for standard test. B) Numerical simulation with $C_{n}^{2}$ and $l_{0}$ from Table 4 .

Cross-correlation peak outcomes established a $61.47 \%$ (see Figure 24) of match, where there occurs a big difference compared with cross-correlation peak results of 3.b. section.

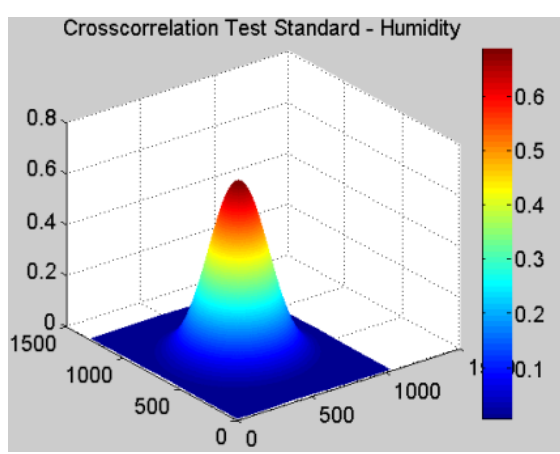

Fig 24. Cross-correlation between experimental and simulation results with $C_{n}^{2}=2.8269 \mathrm{e}-13\left[\mathrm{~m}^{\frac{-2}{3}}\right]$ and $l_{0}=0.0136[\mathrm{~mm}]$.

Finally, inner scale of experiment was introduced at a constant relative humidity in numerical simulation model, resulting as shown in Figure 25B).

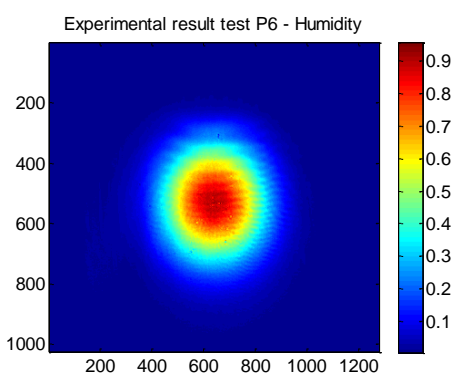

A)

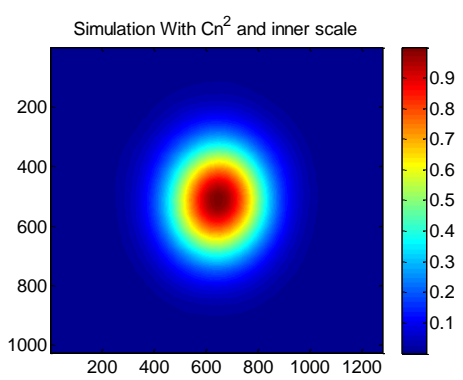

B)

Fig 25. A) Experimental results inside turbulator for P6 test. B) Numerical simulation with $C_{n}^{2}$ and $l_{0}$ from Table 4 .

Finding its cross-correlation peak, we found that was low getting a 58.72\%, smaller compared with result in Section 3.b. 


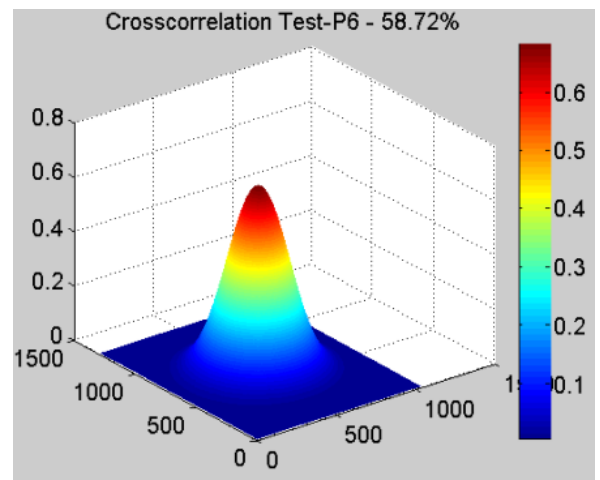

Fig 26. Cross-correlation between experimental and simulation results with $C_{n}^{2}=3.4695 \mathrm{e}-12\left[\mathrm{~m}^{\frac{-2}{3}}\right]$ and $l_{0}=0.0090$ [mm].

Therefore, we proposed to include more parameters such as $C_{T}^{2}, C_{R H}^{2}$ among others, with the aim of achieving better estimation of atmospheric turbulence that is present in the environment.

\section{3. e. Analysis of experimental samples density between simulated samples.}

Because of cross-correlations were low, we proceeded to find area and perimeter of binarized wavefront. They showed greater significance, as in the case with constant temperature of $105^{\circ} \mathrm{C}$, through image processing were found parameters as shown below in Table 5 .

TABLE 5. Results of area and perimeter for each of the wavefronts at constant temperature of $105^{\circ} \mathrm{C}$.

\begin{tabular}{|c|c|c|}
\hline Test & Area (Pixels ${ }^{2}$ ) & Perimeter (pixels) \\
\hline Experimental test $105^{\circ} \mathrm{C}$ & 139407 & 1324 \\
\hline Simulated test introducing $C_{n}^{2}$ & 108053 & 1165 \\
\hline Simulated test introducing $C_{n}^{2}$ and $\boldsymbol{l}_{\mathbf{0}}$ & 148609 & 1367 \\
\hline
\end{tabular}

TABLE 6. Ratio of experimental and simulated results.

\begin{tabular}{|l|c|c|}
\hline Test & Error Area [\%] & Error Perimeter [\%] \\
\hline Experimental / Simulated results introducing $C_{n}^{2}$ & 29.02 & 13.65 \\
\hline Experimental test / Simulated test introducing $C_{n}^{2}$ and $\boldsymbol{l}_{\mathbf{0}}$ & 6.19 & 3.14 \\
\hline
\end{tabular}

As shown in Table 5 and Table 6, area and perimeter values of simulation outcome similar to the experiments when inner scale average was introduced along with $C_{n}{ }^{2}$ average, it pretending that go including parameters related to atmospheric turbulence in numerical simulations; it presents a likeness increasingly for the experimental results.

\section{Conclusions}

- The results in all sections had low cross-correlations peaks, indicating that, we need to include more parameters (such as scintillation, $C_{T}{ }^{2}, C_{R H}{ }^{2}$ among others) in the numerical model to guarantee that under appropriate conditions of atmospheric turbulence, this proposed model is close to real laser beam propagation.

- Despite getting a low cross-correlation between experimental and numerical realizations, it observed that introducing temperature and relative humidity effects on index refraction parameter $C_{n}{ }^{2}$, simulation produce very similar results to actual results as in the case at constant temperature of $105^{\circ} \mathrm{C}$.

- Low correlations are due to they are not ensuring complete description of the turbulence we want to really get, just as it is confirmed that go including parameters, there is an approach to the characteristics of the wavefront images obtained experimentally.

- Future projected work includes missing parameters in numerical simulations, which describe atmospheric turbulence at controlled conditions (i.e. temperature and humidity). 


\section{Acknowledgement}

We acknowledge the support of the Universidad Industrial de Santander UIS, Research and Services Viceprincipal VIE, for funding through the institutional program for consolidation of research groups - year 2013, project 5707 and economical support to attend this conference. We also acknowledge support from Colciencias under project 110256933773: "Uso de la telescopía de Fourier de tiempo promedio para caracterizar la turbulencia horizontal a baja altura", National Call for the Bank of Projects in Science, Technology and Innovation 2012. 0.J. Tíjaro Rojas acknowledges the support from Colciencias under Call number 647 of 2014, for support their doctoral program. H.S. Buenahora acknowledges the support from Colciencias under National Call for innovators and Young Researchers number 706 of 2015. 